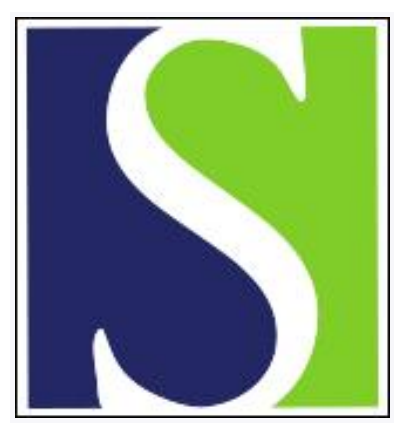

Scand J Work Environ Health 1986;12(6):582-587

https://doi.org/10.5271/sjweh.2099

Issue date: Dec 1986

Muscle activity and fatigue in the shoulder muscles of assembly-plant employees.

by Christensen $\mathrm{H}$

This article in PubMed: www.ncbi.nlm.nih.gov/pubmed/3823806

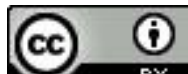




\title{
Muscle activity and fatigue in the shoulder muscles of assembly-plant employees
}

\author{
by Hanne Christensen, $\mathrm{MSc}^{1}$
}

\begin{abstract}
CHRISTENSEN $\mathrm{H}$. Muscle activity and fatigue in the shoulder muscles of assembly-plant employees. Scand J Work Environ Health 12 (1986) 582-587. Subjects who do monotonous and repetitive work in a sitting position often complain of discomfort and soreness in the neck and shoulder regions. Twentyfive subjects had electromyographic examinations of the deltoid, infraspinatus, and trapezius muscles. The recordings were performed eight times throughout a whole workday. In a questionnaire administered before the examinations, $16 \%$ of the subjects had reported pain in the neck only, $8 \%$ pain in the shoulders only, and $48 \%$ pain in both areas. The muscle activity was analyzed by means of the amplitude distribution probability function. The results showed high static contraction levels in the deltoid, infraspinatus, and trapezius muscles and high medium contraction levels of the infraspinatus and trapezius muscles, but acceptable maximum contraction levels for all three muscles. The activity levels did not change during the day and showed no differences related to age or sex. The decrease in mean power frequency during a 2-min contraction sustained at $20 \%$ of the maximal voluntary contraction was the same in the morning and in the afternoon. Although the electrical activity in the muscles indicates a high degree of muscle activity, there was no change during the day, ie, no sign of muscle fatigue.
\end{abstract}

Key terms: amplitude distribution probability function, electromyography, muscle fatigue, power spectrum, shoulder muscles.

Many factory workers work in a sitting position during the whole day. Often the work processes are monotonous and repetitive. During the last few decades complaints of pain and discomfort in the neck and shoulder regions have increased (15).

The electromyogram (EMG) has been used to evaluate muscle activity (10), and an increase in the amplitude, together with a shift in the power spectrum towards lower frequencies, has been used as a determinant of muscle fatigue (12). However, the relation between the amplitude of the EMG and the force level is specific for the subject and for the muscle (7).

Utilizing the EMG, I have evaluated the activity of the shoulder muscles to determine whether muscle fatigue occurred during a workday with monotonous work processes at an assembly plant. Moreover, the possibility of a relation between changes in the EMG and complaints about pain and discomfort in the shoulder and neck region of the subjects was evaluated with the use of a questionnaire.

\section{Subjects and methods}

Twenty-five subjects employed in a modern assembly plant were examined: eight young women (age 19-32 years, height $156-173 \mathrm{~cm}$, weight $46-69 \mathrm{~kg}$, emThe Rehabilitation Institute, University of Copenhagen,
Copenhagen, Denmark.

Reprint requests to: Mr H Christensen, The Rehabilitation Institute, Rigshospitalet, Tagensvej 22, DK 2200 Copenhagen N, Denmark. ployed 3 months -11 years), eight middle-aged women (age 34-58 years, height $161-171 \mathrm{~cm}$, weight $56-82$ $\mathrm{kg}$, employed $4.5-18.2$ years), and nine men (age 2045 years, height $164-193 \mathrm{~cm}$, weight $68-95 \mathrm{~kg}$, employed $0.5-15.3$ years). Informed consent was obtained from all the subjects, and the study was reported to the Science Ethics Committee (Copenhagen) with respect to the Helsinki II declaration.

Twenty-four women worked in the same section of the factory, and $16(67 \%)$ agreed to participate in this study. The womens' job was to assemble printed circuits of different kinds; the assembling process was computerized. The women assembled between 40 and 120 units on one print. Their preferred hand did the assembling, while the other hand took the units from small boxes under the tabletop. From 75 to 100 units were handled in a 5 -min period, and the process demanded coordination. The women had a tendency to work with elevated shoulders.

Twelve men worked in the mens' section, and nine $(75 \%)$ volunteered to participate. The mens' job was a step later in the production process. They soldered the circuit boards together and assembled the chasses. They were either sitting or standing and used a $90^{\circ}$ elbow flexion and a change in pronation and supination in the underarm during the work process. All the measurements were made after a physiotherapist had adjusted the chairs, tables and keyboards to an optimal position for each subject.

The subject's heart rate was recorded via chest electrodes (S\&W, type 888 ) and stored in a portable Memolog $500(11 \times 6.5 \times 3.5 \mathrm{~cm}, 360 \mathrm{~g}$, NOVO electronics). Their rate of perceived exertion was obtained eight times during the day on a nine-point scale (5). 


\section{Questionnaire}

All the subjects answered a standardized questionnaire about pain and discomfort in the neck and shoulder regions (1). The areas of the body for which they were asked to report were illustrated on a figure, ie, the deltoid and the infraspinatus muscles of the shoulder region and the trapezius muscle of the neck region. The questions were answered with yes or no.

\section{Muscle activity}

The muscle activity of each subject was recorded by an EMG with bipolar surface electrodes with a leadoff area of $25 \mathrm{~mm}^{2}$ (Medicotest A-10-VS) over the trapezius muscle (the descending part), the deltoid muscle (the anterior part), and the infraspinatus muscle. The electrodes were placed along the fiber direction. The recordings were made on the right side of the body for right-handed persons and on the left side for left-handed persons. The interelectrode distance was $3 \mathrm{~cm}$, and the interelectrode resistance was kept below $20 \mathrm{k} \Omega$. All the signals were transmitted telemetrically; the transmitters (Medinik) $(5 \times 5 \times 11 \mathrm{~cm})$ were carried in a belt around the waist of the subject. The filter in the amplifier had a lower limit of $2 \mathrm{~Hz}$ and an upper limit of $1800 \mathrm{~Hz}$. The signals were amplified 1000 times (Medinik IC-600-C) and recorded on an FM tape recorder (Brüel \& Kjær 7005). The quality of the signal was controlled continuously on an oscilloscope. All components were powered by a $12-\mathrm{V}$ battery.

\section{Muscle force}

The force of the maximal voluntary contraction (MVC) was measured with a strain-gauge dynamometer (2) with the subject in a sitting position. For the MVC measurement of the deltoid muscle, a strap was fixed around the upper arm above the elbow of the subject and he or she performed maximal shoulder anterior flexion. For the infraspinatus muscle the strap was fixed around the forearm just proximal to the wrist with the elbow joint in $90^{\circ}$ flexion, and an outward rotation at the shoulder joint was performed. For the trapezius muscle the strap was fixed around the shoulder at the acromion, and a maximal bilateral shoulder lift was performed. The maximal torque of the deltoid muscle was 45.4 (32.0-69.9) Newton-meters (Nm) for the young women, $38.5(26.6-57.4) \mathrm{Nm}$ for the middle-aged women, and $71.2(35.5-112.4) \mathrm{Nm}$ for the men. The maximal torque of the infraspinatus muscle was $21.5(14.5-28.0) \mathrm{Nm}$ for both groups of women and $33.5(22.5-45.9) \mathrm{Nm}$ for the men. The MVC of the trapezius muscle was 354 (213-555) N for the young women, $293(162-460) \mathrm{N}$ for the middle-aged women, and $575(391-805) \mathrm{N}$ for the men. There was no statistical difference in maximal force between the two groups of women, but the young women had a lower maximal torque for the deltoid muscle and for the infraspinatus muscle than the men ( $p<0.05$, Student's t-test for independent means).

\section{EMG recordings}

The EMG electrodes were mounted at the start of the day, and maximal muscle strength measurements were performed. The relation between the EMG amplitude and force, the calibration curves, was recorded by visual feedback during a contraction of gradually increasing force in a linear fashion from 0 to $100 \%$ over $10 \mathrm{~s}$. For each muscle three EMG force curves were recorded. Thereafter a contraction of $20 \%$ of the MVC was sustained for $2 \mathrm{~min}$ and recorded for each of the three muscles.

The EMG was recorded during work situations continuously for $10 \mathrm{~min}$ at the start of the workday and for seven 10-min periods throughout the day (before and after each break) during the same part of the work process (figure 1). At the same time the rate of perceived exertion was also obtained. The duration of work processes was noted along with the EMG recordings.

At the end of the day, a 2-min contraction sustained at $20 \%$ of the MVC was repeated for each of the three muscles (figure 1). Due to these experimental procedures the length of the workday was reduced by $1 \mathrm{~h}$ (45 min in the morning when the electrodes were mounted and recordings of muscle strength were performed, and $15 \mathrm{~min}$ in the afternoon when the electrodes were removed).

\section{Signal treatment}

The processing of the EMG was done on a Zilog (PDS 8000 ). The root mean square (rms) of the three calibration curves was analyzed for the first $7 \mathrm{~s}(0-$ $70 \% \mathrm{MVC}$ ) as a means to avoid the influence of muscle fatigue at higher effort. The sampling frequency was $512 \mathrm{~Hz}$, and the time constant $0.12 \mathrm{~s}$. The values of each amplitude and force relation were fitted to a linear function and to a power function (figure 2). There was no difference between the correlation coefficients from these two methods. The calibration curve with the highest correlation coefficient of the power function was used in the analysis of the amplitude distribution probability function (ADPF).

The ADPF was evaluated in the manner described by Jonsson (9). All EMG amplitudes (rms) represent-

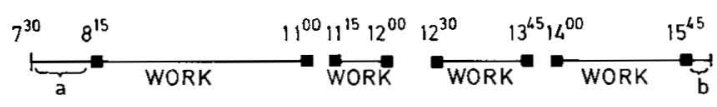

Figure 1. Experimental time schedule. Between 0730 and 0815 (a) the electrodes were mounted and the recording of the maximal voluntary contraction, the calibration curves, and the sustained contractions were made for each muscle. The lines between the recording times ( $\bullet$ ) indicate that the subject was working, while an empty space indicates lunch or a coffee break. Between 1545 and 1600 (b) a contraction sustained for $2 \mathrm{~min}$ was recorded before the electrodes were removed. 


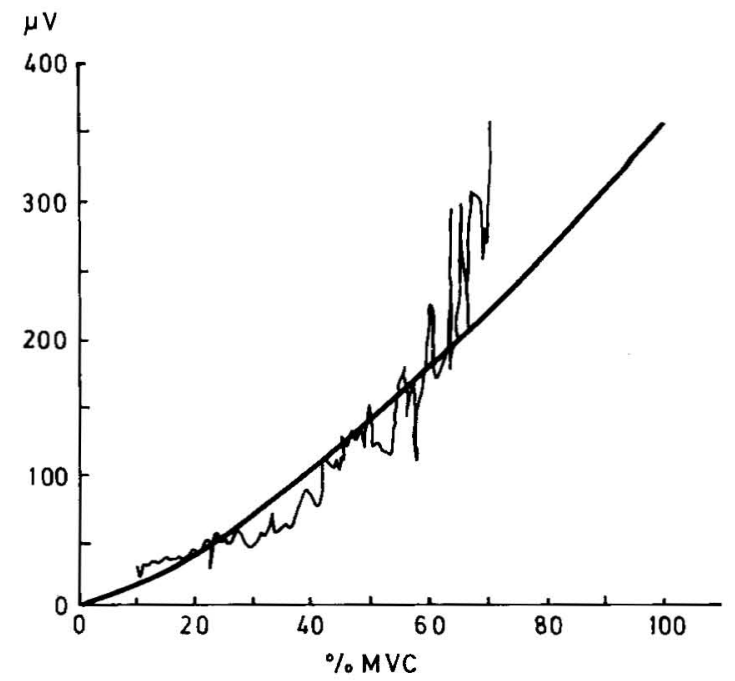

Figure 2. Example of a calibration curve. The amplitude of the electromyogram (EMG) as a function of force, from the infraspinatus muscle. The abcissa is the percentage of maximal voluntary contraction, and the ordinate the electromyographic amplitude expressed in microvolts [linear function: amplitude $(\mu v)=3.43 \times \% M V C+24.67(r=0.920) ;$ power function: amplitude $\left.(\mu v)=14.13 \times \% \mathrm{MVC}^{0.66}(r=0.927)\right] . \quad(\mathrm{MVC}=$ maximal voluntary centraction).

ed in the recording time were converted to the percentage of the MVC from the calibration curve. The ADPF describes the distribution of different levels of contraction. Each point on the distribution function curve indicates the probability that the level of contraction will be lower or equal to the force level in question. A probability of $0.1(p=0.1)$ is defined as the static level of contraction, a probability of $0.5(\mathrm{p}=0.5)$ as the median level of contraction, and a probability of 0.9 $(p=0.9)$ as the maximum level of contraction produced by the muscles during the recording period (9). The ADPF was calculated from the first $4 \mathrm{~min}$ of the recordings of the work cycles. In this way the computer capacity allowed the analysis to be automatic.

The mean power frequency (MPF) of the power spectrum was calculated, with the fast Fourier transformation (14), from the EMG during the sustained contraction at $20 \%$ of the MVC. The power spectrum of the EMG was repeatedly analyzed for a period of $3 \mathrm{~s}$ followed by a 4-s pause during the first $112 \mathrm{~s}$ of the contraction. Each MPF value used was the mean of three successive MPF values. The corresponding amplitude, expressed as rms, was calculated. The sampling frequency was $2048 \mathrm{~Hz}$.

\section{Results}

Forty-eight percent of the subjects reported that they had experienced pain or discomfort in both the neck and shoulder areas, $16 \%$ had trouble in the neck area only, and $8 \%$ had trouble in the shoulders only (table 1). None of the subjects had made any attempt to change their job procedures because of neck or shoulder trouble.

Both groups of women had an increased rate of perceived exertion during the day, the young women reporting an average rating of 1 in the morning and 4 in the afternoon $(\mathrm{p}<0.05)$ and the middle-aged women giving a value of 1 in the morning and 3 in the afternoon $(p<0.05)$. The corresponding change for the men was from 2 in the morning to 3 in the afternoon $(\mathrm{p}<0.05)$.

Heart rate averaged 83 (SD 7) beats/min for all the subjects and did not change during the day.

The ADPF of the EMG signal from the first recording in the morning is shown in figure 3 for each of the three muscles of all the subjects. There was no difference in the ADPF between the three groups of subjects (figure 4). The ADPF did not change in any of the muscles during the day (figure 5), and there was no difference before and after the coffee breaks or lunch. An interindividual analysis showed that, for the deltoid muscle, the static contraction level $(p=0.1)$ decreased with increasing MVC force [maximal force $(\mathrm{N})=195.1-7.5 \times$ static contraction level as the percentage of the MVC] (figure 6). The subjects who had any pain or discomfort in the shoulder had a higher static level ( $7.8 \%$ of the MVC) in the deltoid muscle than those subjects with no pain or discomfort $(4.8 \%$ of the MVC) $(\mathrm{p}<0.05)$. There was no difference in the static level of the three muscles between those subjects with pain in the neck or shoulders for the last few days and those without pain or trouble.

The decrease in MPF was the same for the three muscles $(9 \mathrm{~Hz}$ ) (figure 7 ). The decrease per unit of time was similar in the morning and afternoon recordings (figure 8). The initial value of the trapezius muscle was higher in the morning $(67.5 \mathrm{~Hz})$ than in the afternoon $(59.9 \mathrm{~Hz})(\mathrm{p}<0.05)$. The initial value of the infraspinatus muscle was lower in the morning $(93.8 \mathrm{~Hz})$ than in the afternoon $(108.4 \mathrm{~Hz})(\mathrm{p}<0.05)$.

\section{Discussion}

Sixty-four percent of the subjects stated that they had pain or discomfort in the neck; $56 \%$ reported trouble or pain in the shoulders; $48 \%$ had pain or discomfort in both areas. Bjelle et al (3) reported that among subjects employed in the same type of jobs $8 \%$ had pain or discomfort in the neck and $35 \%$ in the shoulders ( 97 subjects), but he used another questionnaire. The high incidence of neck and shoulder trouble in the present study may be due to the small sample size ( 25 subjects).

The present values for static contraction levels in employees at an assembly plant are similar to those contained in other reports $(6,11,16)$. For an 8 -h workday Björkstén \& Jonsson (4) have recommended the following upper limits for the various levels of contraction: $2-5 \%$ of the MVC for the static contrac- 
Table 1. Results of the questionnaire indicating pain and discomfort in the shoulder and neck.

\begin{tabular}{|c|c|c|c|c|c|c|c|c|}
\hline & \multicolumn{2}{|c|}{$\begin{array}{l}\text { Young women } \\
(\mathrm{N}=8)\end{array}$} & \multicolumn{2}{|c|}{$\begin{array}{l}\text { Middle-aged } \\
\text { women } \\
(\mathrm{N}=8)\end{array}$} & \multicolumn{2}{|c|}{$\begin{array}{c}\text { Men } \\
(\mathrm{N}=9)\end{array}$} & \multicolumn{2}{|c|}{$\begin{array}{c}\text { Total } \\
(N=25)\end{array}$} \\
\hline & Shoulder & Neck & Shoulder & Neck & Shoulder & Neck & Shoulder & Neck \\
\hline Any pain or discomfort & 6 & 7 & 6 & 5 & 2 & 4 & 14 & 1 \\
\hline $\begin{array}{l}\text { Discomfort during the last } \\
12 \text { months }\end{array}$ & 5 & 7 & 4 & 5 & 1 & 3 & 10 & 1 \\
\hline $\begin{array}{l}\text { Discomfort for more than } \\
8 \mathrm{~d} \text { during the last } \\
12 \text { months }\end{array}$ & 5 & 5 & 4 & 5 & 1 & 0 & 10 & 1 \\
\hline $\begin{array}{l}\text { Discomfort for more than } \\
30 \text { d during the last } \\
12 \text { months }\end{array}$ & 2 & 3 & 3 & 3 & 1 & 0 & 6 & 6 \\
\hline Pain during the last few days & 2 & 4 & 4 & 4 & 0 & 1 & 6 & 9 \\
\hline Pain every day & 0 & 0 & 1 & 1 & 0 & 0 & 1 & 1 \\
\hline
\end{tabular}

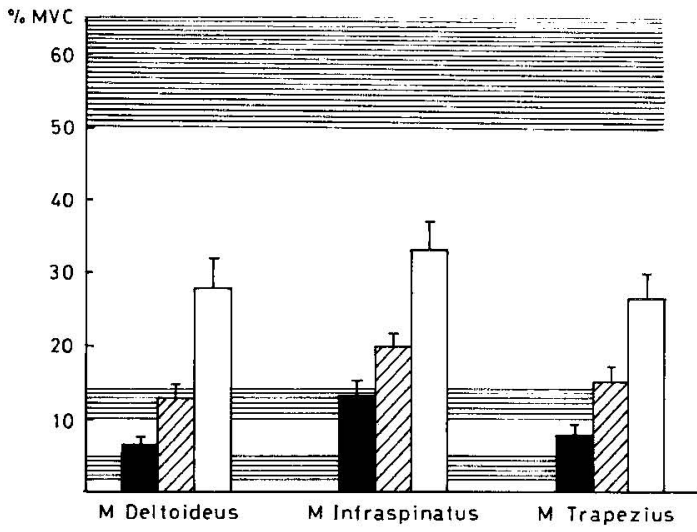

Figure 3. Mean of the amplitude distribution probability functions of the deltoid, infraspinatus, and trapezius muscles of 25 subjects in the morning of the workday. The black columns show the static activity level $(p=0.1)$, the hatched columns the median activity level ( $p=0.5$ ), and the empty columns the maximal activity level $(p=0.9)$. The vertical bars represent one standard error of the mean. The lowest horizontal lines indicate the limits for the static activity level $[2-5 \%$ of the maximal voluntary contraction (MVC)], the middle set of horizontal lines the limits for the middle activity level (10-14\% of the MVC), and the upper most horizontal lines the limits for maximal activity $(50-70 \%$ of the MVC) as suggested by Björkstén \& Jonsson (4).

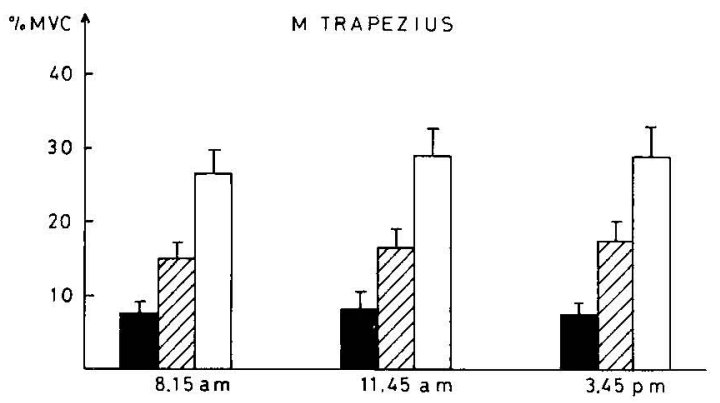

Figure 5. Mean of the amplitude distribution probability function of the trapezius muscle for the 25 subjects at $0815(8.15$ am), 1145 (11.45 am), and 1545 (3.45 pm). The black columns indicate the static activity level $(p=0.1)$, the hatched columns the middle activity level $(p=0.5)$, and the empty columns the maximal activity level $(p=0.9)$. The vertical bars represent one standard error of the mean.

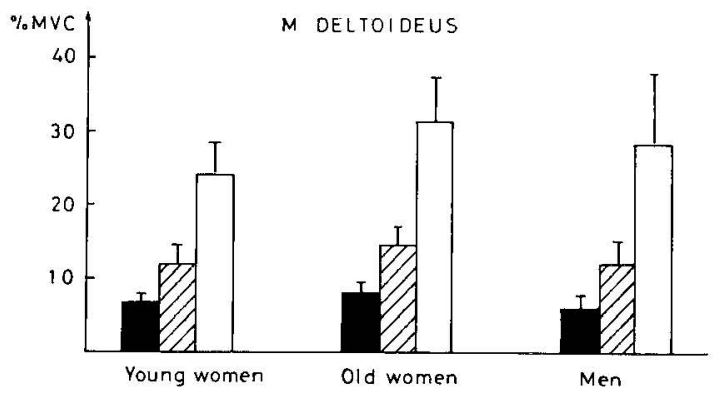

Figure 4. Mean of the amplitude distribution probability function of the deltoid muscle of the eight young women, the eight middle-aged (old) women, and the nine men in the morning. The black columns indicate the static activity level $(p=0.1)$, the hatched columns the median activity level $(p=0.5)$, and the empty columns the maximal activity level $(p=0.9)$. The vertical bars represent one standard error of the mean.

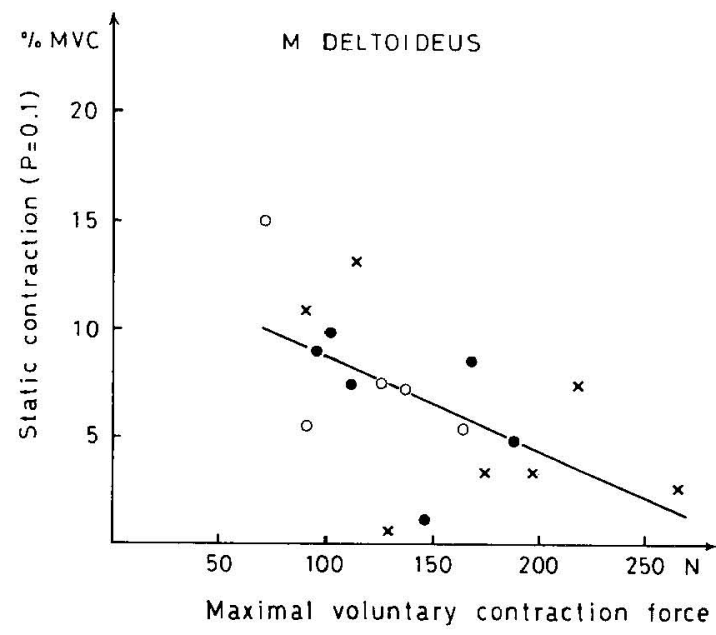

Figure 6. Relation between the static contraction force $(p=0.1)$ and the maximal voluntary contraction force of the deltoid muscle. [Maximal force $(\mathrm{N})=195.1-7.5 \times$ static con. traction level (\%MVC) $(r=0.5683, p<0.05)](\bullet=$ young women, $O=$ middle-aged women, $x=$ men). 


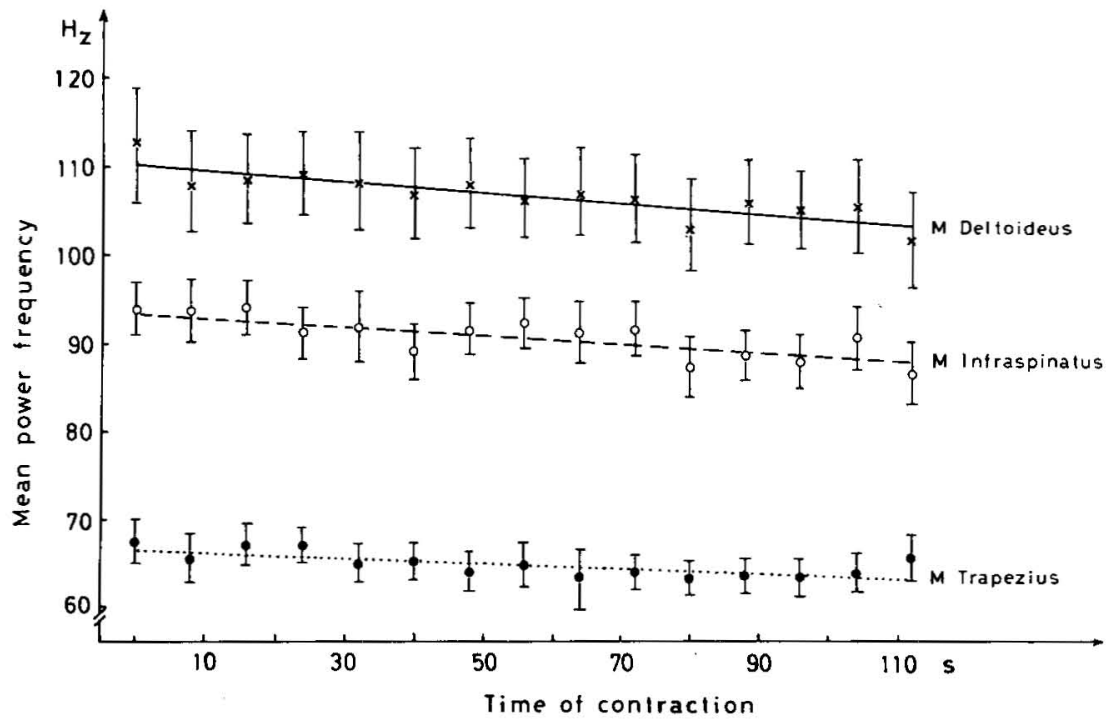

Figure 7. Mean power frequency during 2 min of contraction sustained at $20 \%$ of the maximal voluntary contraction in the morning. Each point is the mean of the 25 subjects. The vertical bars represent one standard error of the mean.

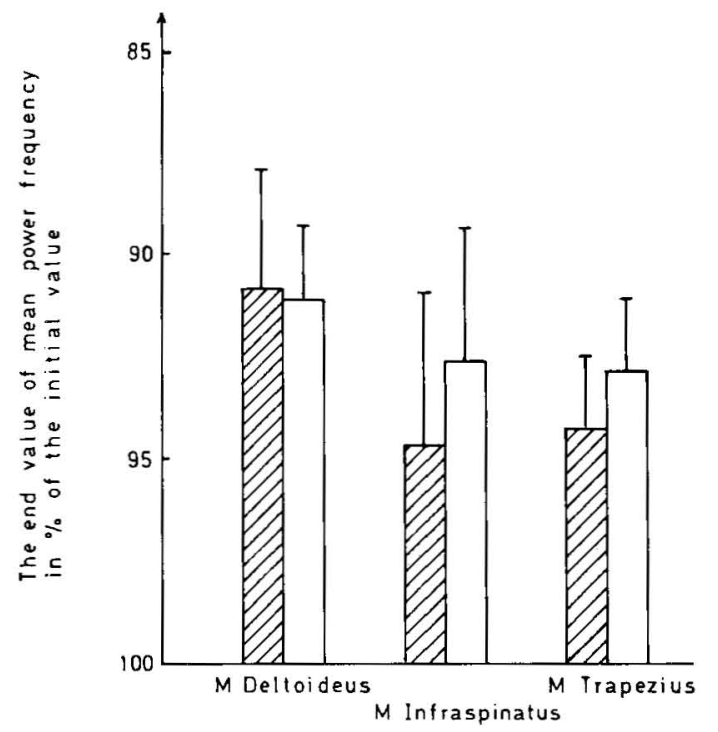

Figure 8. The end value of the mean power frequency as the percentage of the initial value of 2 min of contraction sustained at $20 \%$ of the maximal voluntary contraction in the morning (hatched columns) and in the afternoon (empty columns). The vertical bars represent one standard error of the mean.

tion level $(p=0.1), 10-14 \%$ of the MVC for the median contraction level $(\mathrm{p}=0.5)$, and $50-70 \%$ of the MVC for the maximal contraction level $(p=0.9)$ (figure 3). According to these limits, the static contraction level seen in this study was too high for all three muscles (deltoid $6.6 \%$, infraspinatus $13.2 \%$, and trapezius $7.4 \%$ of the MVC), and the median contraction level was too high for the infraspinatus (19.9\% of the MVC) and trapezius (14.9\% of the $\mathrm{MVC}$ ) muscles. These high activity levels of the muscles in the shoulder and neck areas could be why the sub- jects reported a high incidence of discomfort and pain.

The relation between the static contraction level $(\mathrm{p}=0.1)$ and the MVC force is due to the fact that one uses relatively more force to do the same amount of work as the MVC decreases. In this study there was no statistical difference between the groups of young and middle-aged women, in either maximal force or in ADPF, although this finding should be expected since the maximal force diminishes with increasing age and is lower in women than in men (8). The men of the present study had a higher maximal force than the women, but there was no difference in ADPF. The muscles used for the recordings are relatively small, and there is probably no age-related difference in their performance.

There was no difference in the ADPF during the day for any of the groups or for any of the muscles. When a muscle contracts at a certain level of activity for $10 \%$ of the recording time during the work process, according to the static level of contraction, there is a certain number of pauses. This phenomenon reduces the amount of muscle fatigue. The (ADPF) method is useful when one wants to express muscle activity during work situations, but not when the problem is to express changes in the pattern of activity, as already discussed by Kahabka (13).

As shown previously by Kadefors et al (12), as well as in the present study, the MPF decreased with time during a sustained contraction. There was no difference in the decrease in the MPF from morning to afternoon. This finding indicates that the muscles involved were able to perform this contraction in the same way at the beginning and the end of the workday. I cannot explain the finding of a high initial MPF value for the infraspinatus muscle in the afternoon and a lower one for the trapezius muscle. 
In conclusion, the questionnaire part of this study showed that computerized assembly-plant work may involve a high incidence of pain and discomfort in the shoulders and neck. The EMG signals showed a correspondingly high degree of muscle activity during the work. The ADPF is a valuable method with which to estimate actual muscle activity during work situations, but it is not suited for recording possible muscle fatigue. The results were independent of the time of day the recordings were performed.

Despite the subjects' subjective experience of fatigue in the shoulder muscles at the end of the day, the EMG signals from the shoulder muscles did not reveal any evidence of muscle fatigue in either the amplitude or frequency analysis.

\section{Acknowledgments}

This study was supported by The Working Environment Foundation, Denmark. The Rheumatism Association, the Jacob Madsens and Wife Foundation, the P Carl Petersen Foundation, and the Health Insurance Foundation are also gratefully acknowledged for their support.

The author wishes to thank all the subjects and $\mathrm{L}$ Rasmussen, occupational physiotherapist (Brüel \& Kjær), for their kind cooperation. R Anker, D Lütken, and B Pollner, physiotherapists, are thanked for their skillful description of the work processes. I thank Dr A Fuglsang-Frederiksen, Hvidovre Hospital, Dr D Roos and Dr E Nygaard, The Rehabilitation Institute (Copenhagen), for their helpful suggestions in the preparation of the manuscript.

\section{References}

1. Andersson G, Biering-Sørensen F, Hermansen L, Jonsson B, Jørgensen K, Kilbom Å, Kuorinka I, Vinterberg $H$. Nordiska frageformulär för kartläggning av yrkesrelaterade muskuloskeletala besvär [Standardized Nordic questionnaires for the analysis of musculoskeletal symptoms]. Nord Med 99 (1984): 2, 54-55.

2. Asmussen E, Heebrll-Nielsen K, Molbech S. Methods for evaluation of muscle strength. Commun Test Obs Inst Dan Natl Assoc Infant Paralysis 5 (1959) 3-13.

3. Bjelle A, Hagberg M, Michaelsson G. Occupational and individual factors in acute shoulder-neck disorders among industrial workers. $\mathrm{Br} \mathrm{J}$ Ind Med 38 (1981) $356-363$

4. Björkstén M, Jonsson B. Endurance limit of force in long-term intermittent static contractions. Scand J Work Environ Health 3 (1977) 23-27.

5. Borg GAV. Psychophysical bases of perceived exertion. Med Sci Sport Exercise 14 (1982) 277-281.

6. Christensen H. Muscle activity and fatigue in the shoulder muscles during repetitive work: An electromyographic study. Eur J Appl Physiol Occup Physiol (in press).

7. Christensen H, Lo Monaco M, Dahl K, FuglsangFrederiksen A. Processing of electrical activity in human muscle during a gradual increase in force. Electroenceph Clin Neurophysiol 58 (1984) 230-239.

8. Fuglsang-Frederiksen A. Electrical activity and force during voluntary contraction of normal and diseased muscle. Acta Neurol Scand 63 (1981): suppl 83, 1-60.

9. Jonsson B. Evaluation of the myoelectric signal in longterm vocational electromyography. Biomechanics V-A (1976) $509-514$.

10. Jonsson B. Kinesiology: With reference to electromyographic kinesiology. Contemp Clin Neurophysiol (1978): suppl 34, 417-428.

11. Jonsson B, Andersson G, Winkel J, Engdal S, Hedberg G. Sittande arbetsställningar [Sitting working postures]. Arbetarskyddsstyrelsen, Solna 1984. (Utbildning 6).

12. Kadefors R, Kaiser E, Petersén I. Dynamic spectrum analysis of myopotentials and with special reference to muscle fatigue. Electromyography 8 (1968) 39-74.

13. Kahabka G. Erweiterung arbeitswissenschaftlicher Methodik durch differenzierte Elektromyographie. VDIVerlag, Düsseldorf 1984.

14. Lindström L, Magnusson R, Petersén I. Muscular fatigue and action potential conduction velocity changes studied with frequency analysis of EMG signals. Electromyography 10 (1970) 341-353.

15. Luopajärvi T, Kuorinka I, Virolainen M, Holmberg $\mathbf{M}$. Prevalence of tenosynovitis and other injuries of the upper extremities in repetitive work. Scand J Work Environ Health 5 (1979): suppl 3, 48-55.

16. Onishi M, Sakai K, Kogi K. Arm and shoulder muscle load in various keyboard operating jobs of women. $J$ Hum Ergol 11 (1982) 89-97.

Received for publication: 25 February 1986 